See discussions, stats, and author profiles for this publication at: https://www.researchgate.net/publication/316855697

\title{
A survey to establish current practice in addressing work participation with inflammatory arthritis in the Irish clinical setting
}

Article in Musculoskeletal Care · May 2017

DOI: $10.1002 / \mathrm{msc} .1198$

\section{CITATIONS}

0

4 authors, including:

\section{Yvonne Codd}

Trinity College Dublin \& Naas General Hospital

23 PUBLICATIONS 13 CITATIONS

SEE PROFILE

Ronan H Mullan

Trinity College Dublin

86 PUBLICATIONS 852 CITATIONS

SEE PROFILE
133

Tadhg Stapleton

Trinity College Dublin

40 PUBLICATIONS 208 CITATIONS

SEE PROFILE

Some of the authors of this publication are also working on these related projects:

To explore the impacts of newly diagnosed inflammatory arthritis on participation and explore how current services address participation and engagement on an occupational level among service users attending MDT-led early arthritis clinics. View project

Koebner phenomenon of Bone in Sarcoidosis View project 


\title{
A survey to establish current practice in addressing work participation with inflammatory arthritis in the Irish clinical setting
}

\section{Yvonne Codd $^{1,2}$ | Tadhg Stapleton ${ }^{1}$ | David Kane ${ }^{2}$ | Ronan Mullan ${ }^{2}$}

\author{
${ }^{1}$ Discipline of Occupational Therapy, School of Medicine, Trinity College, University of Dublin, Dublin, Ireland \\ ${ }^{2}$ Rheumatology Departments, Naas and Tallaght Hospitals, Dublin, Ireland \\ Correspondence \\ Yvonne Codd, Discipline of Occupational Therapy, School of Medicine, Trinity \\ College, University of Dublin, Dublin, Ireland \\ Email: mooneyy@tcd.ie
}

\section{1 | BACKGROUND}

Inflammatory arthritis (IA) is a complex progressive disease, with 2,250 cases diagnosed in Ireland annually (Kane \& Kavanagh, 2011) and an average age at onset of 35-45 years (Health Service Executive, 2015). International guidelines recommend that clinical management maximizes health-related quality of life, including maintaining work ability (Combe et al., 2007; National Institute of Clinical Excellence, 2009). It is recognized that participation in paid employment is affected in the early phases of IA and there is a need for increased early support for participation and engagement in work, to ensure improved quality of life outcomes (Codd, Stapleton, Veale, FitzGerald, \& Bresnihan, 2010). Research into work disability has recognized the impacts of the diagnosis on occupational performance and participation (Codd et al., 2010; Forsyth et al., 2006; Prior \& Hammond, 2013). Addressing work issues among people with $I A$ in an organized and timely manner is important, although implementation of this in practice is inconsistent and fragmented (Lacaille et al., 2007; Hoving, et al., 2013; Walker-Bone \& Black, 2016).

The American Occupational Therapy Association (2014) practice framework (third edition) identified work as a domain of concern for occupational therapists. UK and Irish surveys examined the perspectives of rheumatology occupational therapists on the provision of work support in clinical practice (Prior \& Hammond, 2014; Corcoran et al., 2015). It was found that $64 \%$ of referrals were work related (Corcoran et al., 2015), and that one-third of respondents to the UK survey did not provide vocational rehabilitation (Prior \& Hammond, 2014). These studies reaffirmed the challenge of providing equitable and highquality occupational therapy work support to this population. International standards recommend the provision of work support, yet variances in the provision of clinical services remain. To date, there has been no examination of multidisciplinary team members' influences in referral to work participation. The present study aimed to compare recommendations for practice by scoping patterns of work referral, and the work support currently available in rheumatology services across Ireland for people with IA and identifying factors which help or hinder provision. We also aimed and to explore the role of occupational therapy in addressing work from the rheumatology teams' perspectives, including current practices and challenges.

\section{2 | METHODS}

Data were gathered using an online survey. A questionnaire was designed specifically to compare the service context in Ireland by the first two authors. It was informed by the literature on best practice work-related interventions and by previous studies in Ireland and the UK from occupational therapists' perspectives (Prior \& Hammond, 2014; Corcoran et al., 2015). Piloting was completed, to check for clarity, face validity and the appropriateness of questions. The study sample consisted of medical and healthcare professionals working in clinical rheumatology. The survey participants were identified through professional societies - namely, the Irish Society for Rheumatology, Irish Society for Chartered Physiotherapists and Irish Rheumatology Nursing Forum.

Ethical approval to conduct the research was obtained from the research ethics committee from the School of Medicine, Trinity College, Dublin. Data collection was completed between January and March 2016.

\section{3 | RESULTS}

A total of 73 responses were received from 25 nurses, 18 doctors and 30 physiotherapists, indicating a response rate of approximately $22 \%$. 


\subsection{Profile of rheumatology population}

Respondents indicated that $71 \%$ of service users were of working age, and $55 \%$ of respondents $(n=40$ ) estimated that $25-49 \%$ of their caseload had work needs requiring intervention. In addition, $23 \%$ of respondents $(n=16)$ identified that over $50 \%$ of rheumatology clients in their services had work needs. The age demographic and proportion of clients with work needs are shown in Figures 1 and 2.

The majority of respondents (95\%) agreed that addressing employment retention was within the remit of clinical rheumatology practitioners.

Of the total sample, $66 \%(n=48)$ reported that work needs were currently supported within their rheumatology services. Respondents were asked to indicate on a rating scale how well the current services in which they worked supported clients' work needs (from $0=$ not at all well, to 10 = extremely well) (see Figure 3 ).

The majority of respondents $(67 \%)$ scored 5 or less, perhaps indicating a less than satisfactory level of support with work needs in current clinical rheumatology services.

\subsection{Current rheumatology practice in addressing work}

The majority of respondents $(81 \%, n=59)$ reported that they routinely asked clients at their first appointment about work status and work ability. However, fewer addressed work issues at subsequent appointments $(56 \%, n=41)$. It may be the case that work is asked about as part of the initial interview, but there is less emphasis on work-based interventions, and therefore it is addressed less frequently at subsequent appointments.

Respondents indicated that work issues were most likely to be addressed if the client initiated a conversation about work concerns $(94 \%, n=68)$ or reported work absenteeism (83\%, $n=60)$, or if a client's work involved a physical component $(75 \%, n=55)$. Work issues were least likely to be addressed by the team if the client had had IA for more than 5 years $(56 \%, n=41)$, had mechanical joint changes $(40 \%, n=29)$, or was in the early stages of their disease (39\%, $n=28)$.

The current barriers to addressing work were identified as limited time in the clinical setting $(92 \%, n=67)$, lack of familiarity with best practice for work support $(91 \%, n=66)$ and lack of perceived competency to assess the complexities of work $(82 \%, n=59)$.

Qualitative comments received from the open-ended questions highlight the influence of:

- Time pressure at appointments;

- Uncertainty regarding the optimal timing of addressing work in the disease management pathway;

- Work disability has already occurred.

Quotes included:

It is opportunistic. In the context of a busy service it really is more when patients bring it up.
FIGURE 1 Age demographic of rheumatology service users
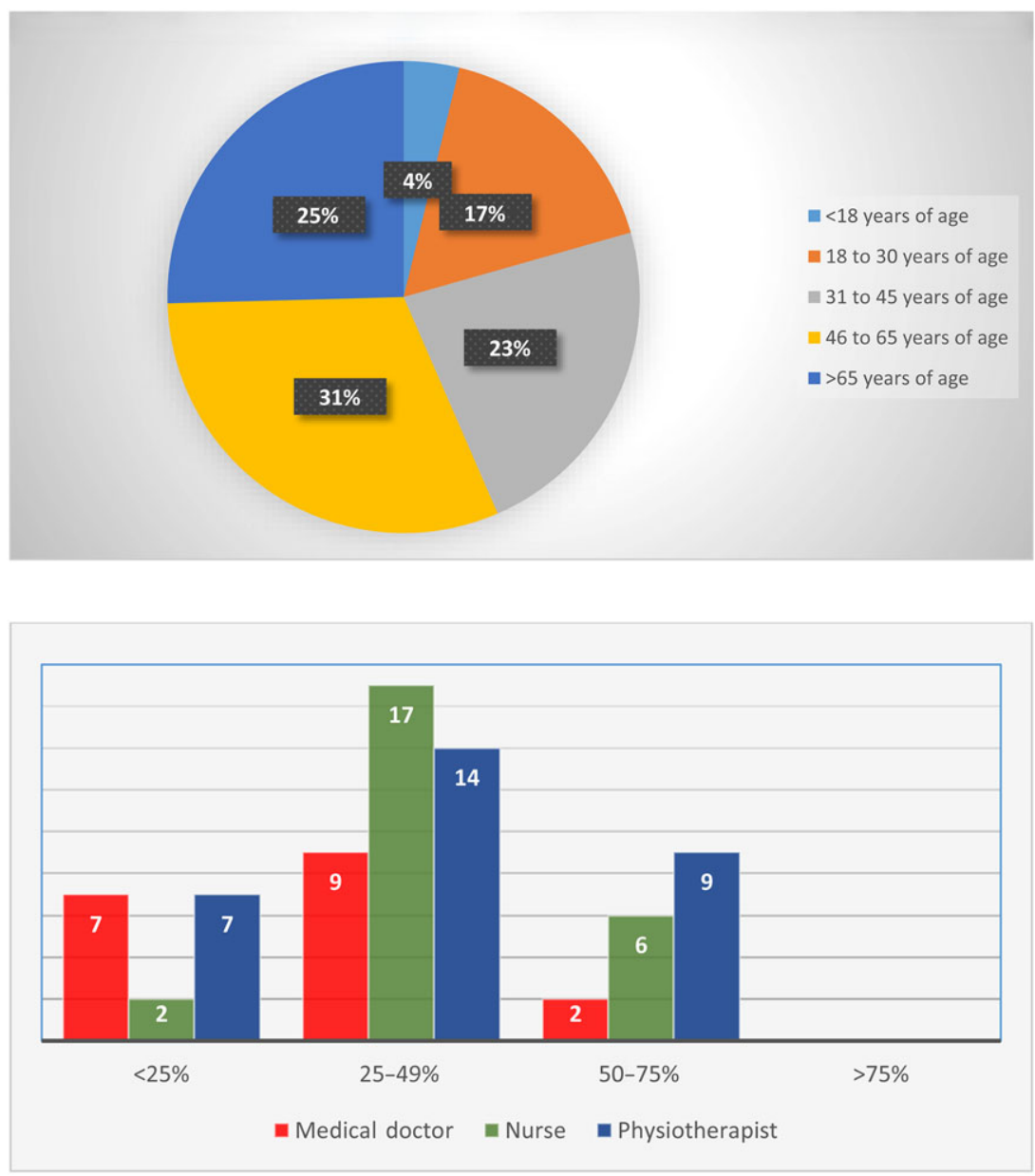


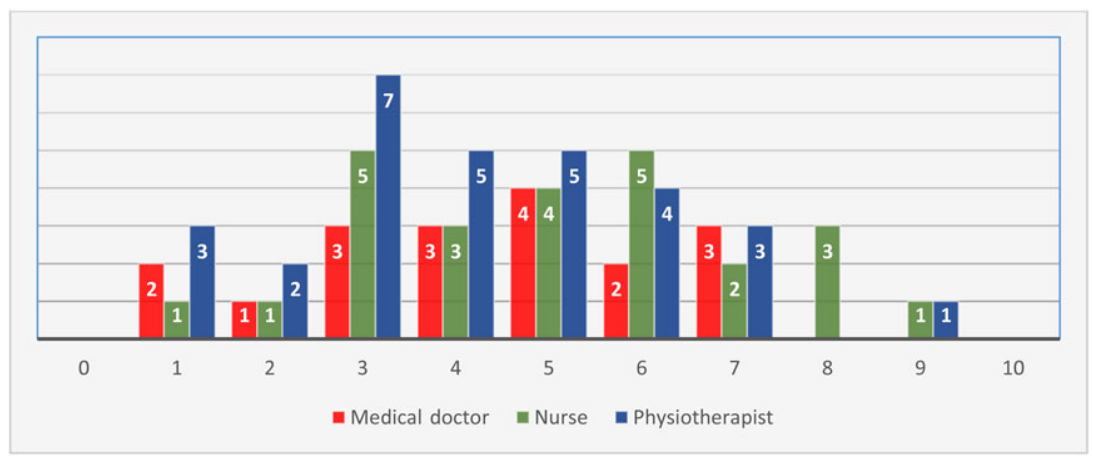

FIGURE 3 How well are work needs currently supported? $(0=$ not at all well to $10=$ extremely well)

The timing piece is unclear to me. When should we refer about work?

I do not know where to signpost them to if there is a problem, so I do not tend to raise it myself.

Many respondents differentiated between asking about work versus providing an intervention on work retention. Although work may have been addressed during assessment, typically it was not included in an intervention, or a limited work-based intervention was offered:

Patients may be asked about their work issues regularly but addressing the issue is not as routine.

\subsection{Rheumatology occupational therapy and work}

Occupational therapy was identified as the most appropriate profession for addressing work issues $(78 \%, n=57)$.

Traditional rheumatology occupational therapy roles (splinting 98\%, activities of daily living (ADL) 94\%, joint protection $87 \%$ ) remained as top reasons for referral. Work-related issues accounted for $55 \%$ ( $n=40$ ) of referrals to occupational therapy by respondents. Within current service organization, respondents indicated that work interventions currently provided by occupational therapy services included:

- Provision of solutions for work-based problems (62\%);

- Applying lifestyle balance skills, including coping and self-management (61\%);

- Advice on retraining and/or return to work (55\%);

- Customizing condition management skills specifically to match the work tasks of clients (52\%).

Respondents also identified the potential roles of occupational therapists in expanding existing work interventions to support employment retention through the provision of work-related legislation advice (73\%), liaison with co-workers/employers (75\%), applying selfadvocacy skills including negotiation and communication skills (66\%) and advice on social benefits (65\%).

\subsection{Barriers to referral to occupational therapy for work support}

Although many respondents reported regular referral to occupational therapy for work issues, $51 \%$ of respondents $(n=37)$ reported not routinely referring to occupational therapy for work support due to:
- Limited availability of occupational therapy (13\% of responders having no access);

- Uncertainty regarding the optimum timing for work intervention;

- Lack of referral pathway for work;

- Uncertainty as to what occupational therapy might offer.

The qualitative comments received highlighted the influences of multidisciplinary team knowledge - gaps in the occupational therapy role; a limited occupational therapy service, causing vetting of referrals; and the view that work support is desirable/specialist rather than core occupational therapy practice in rheumatology:

We need early access to OTs specializing in supporting patients to return to the workforce and to remain in the workforce by re-skilling or retraining. Currently, when we refer them to OT, often the basic needs take priority e.g. splinting or aids to support in daily activities - and there is little focus on long-term follow-up of workrelated issues.

\subsection{Potential strategies to improve rheumatology work-related services}

Participants were asked to rate a series of suggestions regarding the organization of work-related services to improve their existing rheumatology service. The main results were:

- Educate referrers as to what work support is available within the current service (82\%);

- Implement a pathway that emphasizes work as a core component addressed from diagnosis (64\%);

- Upskill current staffing to address work need (64\%);

- Develop an outreach work support service (63\%).

\section{4 | DISCUSSION}

The aim of work intervention is to reduce work disability and support work participation as a meaningful and valued role for individuals and for society. While international standards recommend the provision of work support (Combe et al., 2007; National Institute of Clinical 
Excellence, 2009), variances remain in clinical services currently, as studies report that approximately one-third of occupational therapy services do not provide work interventions (Prior \& Hammond, 2014; Corcoran et al., 2015). The current study highlighted an extensive need for work-related support, as more than $70 \%$ of the population were identified as being of working age. Supporting patients of working age to participate in a work role is an integral role and responsibility of rheumatology clinicians and is on the agenda for the Fit for Work Coalition (Bevan, 2015).

A large proportion of respondents $(78 \%, n=57)$ indicated work needs among their caseload, with up to $75 \%$ having work issues. This reflects findings from other studies highlighting the impact of IA on work ability (Bakland, Gran, Becker-Merok, Nordvag, \& Nossent, 2011; Hallert, Husberg, \& Bernfort, 2012; Tillett, de-Vries, \& McHugh, 2012). This high incidence of work needs within a working population poses a significant challenge to current services to deliver meaningful interventions to support work participation.

Respondents in the present study recognized the importance of asking about work, although there was extensive variation in addressing work-related issues. Despite services providing some level of work support, overall current provision was deemed suboptimal. There was a growing awareness among respondents of the need to include work issues in the early management of IA, supporting previous research calling for rheumatologists to support early referral for work intervention when required (Gilworth, Haigh, Tennant, Chamberlain, \& Harvey, 2001; Walker-Bone \& Black, 2016). Qualitative comments recognized that asking about work is not the same as actively addressing work within interventions, and that an improvement in active work support is required to increase work ability and role retention.

Findings from the present study suggested that the multidisciplinary team is not directive on addressing work ability, and typically only addresses work issues when raised by the client. Walker-Bone and Black (2016) advocated that clinicians ask about work at every appointment, and explore work barriers. The current study highlighted a need to heighten rheumatology teams' awareness of the importance of addressing work issues early and to signpost appropriately to services, to meet these needs and support work retention. Furthermore, teams should be more directive in addressing work issues in accordance with international guidelines (Combe et al., 2007; National Institute of Clinical Excellence, 2009).

The current findings reflected some confusion on the part of the rheumatology team as to the optimal timing to address work; this timing uncertainty was identified as having a negative impact on the coordination of work services. This timing issue does not follow the guidelines advocating early intervention to support favourable outcomes for work retention (Combe et al., 2007; EUMUSC.net, 2013; National Institute of Clinical Excellence, 2009).

Respondents recognized that supporting work should be embedded in core management from the initial diagnosis. The concept of a pathway for work was recommended by respondents as a useful way to manage work needs. Implementation of a pathway for work would alleviate subjective variances, which might influence work being addressed and provide an equitable, timely service.
Prior and Hammond (2014) suggested a National Health Servicewide referral pathway to rheumatology occupational therapy vocational rehabilitation. Findings in the present study reflect issues raised by Prior and Hammond (2014) and support the implementation of a similar pathway in services in Ireland. This proposed pathway would support equitable service access and strengthen the confidence of multidisciplinary team members to address work ability as they would have a clear pathway through which to manage the work needs identified.

Addressing work participation is recognized has having the potential to reduce work disability (Franche et al., 2005; Waddell, Burton, \& Kendall, 2008). Studies have examined the role of occupational therapy in vocational rehabilitation (Bade \& Eckert, 2008; Lee \& Kielhofner, 2009; WFOT, 2012; Hammond, Prior, O'Brien, Woodbridge, \& Radford, 2014). The present study identified barriers to the provision of work interventions by occupational therapists, including time and resource restrictions and the lack of a referral process for work, which reportedly account for high levels of unmet need. Work is recognized as a domain of concern for occupational therapy (American Occupational Therapy Association, 2014), yet the current findings suggested that, due to limited service availability, work issues do not appear to be prioritized consistently in early intervention, and that symptom management approaches appear to take priority.

Several limitations to the present study have implications for the generalizability of the conclusions reached. A response rate of $22 \%$ could be viewed as a limitation. There was an equal number of responses across the three professions, so findings are unlikely to be overly influenced by one professional subgroup. Literature on response rates in online surveys suggest that rates of $10-20 \%$ among health professionals are not uncommon (Flanigan et al., 2008; Dykema et al., 2013).

\section{5 | CONCLUSION}

The present study on work participation support in rheumatology reinforces the evidence that service provision is inequitable and varied. Work needs tend to be addressed within current services only when the client initiates the issue. The majority of respondents viewed employment support as within the remit of rheumatology but perceived a lack of resources in relation to time, staffing and expertise. Although some services provided work support, overall current provision was deemed suboptimal and dependent on subjective variables. The opportunity exists to improve the timing and quality of services to address work early in the disease, in line with international standards, including through educating the multidisciplinary team as to the work support interventions that are available within services, and when and how to access them, and through the implementation of a clinical pathway for employment retention.

\section{ACKNOWLEDGEMENTS}

The authors thank the rheumatology doctors, nurses and physiotherapists who participated in the study. 


\section{REFERENCES}

American Occupational Therapy Association (2014). Occupational therapy practice framework: Domain and process (3rd edition). American Journal of Occupational Therapy, 68(Suppl. 1), S1-S48. https://doi.org/ 10.5014/ajot.2014.682005

Bade, S., \& Eckert, J. (2008). Occupational therapists' critical value in work rehabilitation and ergonomics. Work: A Journal of Prevention, Assessment and Rehabilitation, 31(1), 101-111.

Bakland, G., Gran, J. T., Becker-Merok, A., Nordvag, B. Y., \& Nossent, J. C. (2011). Work disability in patients with ankylosing spondylitis in Norway. Journal of Rheumatology, 38(3), 479-484. https://doi.org/ 10.3899/jrheum.100686

Bevan, S. (2015). Economic impact of musculoskeletal disorders (MSDs) on work in Europe. Best Practice \& Research. Clinical Rheumatology, 29(3), 356-373. https://doi.org/10.1016/j.berh.2015.08.002

Codd, Y., Stapleton, T., Veale, D. J., FitzGerald, O., \& Bresnihan, B. (2010). A qualitative study of work participation in early rheumatoid arthritis. International Journal of Therapy and Rehabilitation, 17(1), 24-32.

Combe, B., Landewe, R., Lukas, C., Bolosiu, H. D., Breedveld, F., Dougados, M., ... Yazici, H. (2007). EULAR recommendations for the management of early arthritis: Report of a task force of the European standing Committee for International Studies Including Therapeutics (ESCISIT). Annals of the Rheumatic Diseases, 66(1), 34-45. https://doi.org/ 10.1136/ard.2005.044354

Corcoran, O., Fitzgerald, T., Codd, Y., Brownlee, J., Verling, N., McCausland, K., ... Duggan, E. (2015). The landscape of rheumatology occupational therapy in vocational rehabilitation in Ireland. Conference Poster Presentation at the Irish Society for Rheumatology/Irish Rheumatology Health Professional Society Autumn Conference.

Dykema, J., Jones, N. R., Piche, T., \& Stevenson, J. (2013). Surveying clinicians by web: Current issues in design and administration. Evaluation and the Health Professions, 36(3), 352-381. https://doi.org/10.1177/ 0163278713496630

Eumusc.net (2013). Eumusc.net standards of care for people with rheumatoid arthritis. Retrieved from http://www.eumusc.net/myUploadData/ files/RA_Full_draft_FINAL_V2[1].pdf

Flanigan, T., McFarlane, E., \& Cook, S. (2008). Conducting survey research among physicians and other medical professions - a review of current literature. In Proceedings of the Survey Research Methods Section on Survey Research Methods, American Association for Public Opinion Research, 4136-4147.

Forsyth, K., Bravemann, B., Kielhofner, G., Ekbladh, E., Haglund, L., Fenger, K., \& Keller, J. (2006). Psychometric properties of the worker role interview. Work, 27(3), 313-318.

Franche, R. L., Cullen, K., Clarke, J., Irvin, E., Sinclair, S., \& Frank, J. (2005). Workplace-based return-to-work interventions: A systematic review of the quantitative literature. Journal of Occupational Rehabilitation, 15(4), 607-631. https://doi.org/10.1007/s10926-005-8038-8

Gilworth, G., Haigh, R., Tennant, A., Chamberlain, M. A., \& Harvey, A. R. (2001). Do rheumatologists recognize their patients' work-related problems? Rheumatology, 40(11), 1206-1210.

Hallert, E., Husberg, M., \& Bernfort, L. (2012). The incidence of permanent work disability in patients with rheumatoid arthritis in Sweden 19902012: Before and after introduction of biologic agents. Rheumatology, 51(2), 338-346. https://doi.org/10.1093/rheumatology/ker332
Hammond, A., Prior, Y., O'Brien, R., Woodbridge, S., \& Radford, K. (2014). Work rehabilitation in inflammatory arthritis: A pilot randomised controlled trial. Conference Poster Presentation at the EULAR Conference, 11-14 June. Paris: France. http://www.congress.eular.org/ congress_2014.cfm

Health Service Executive. (2015). National clinical care programme for rheumatology CSPD model of care for rheumatic and musculoskeletal disorders, V.9. Retrieved from http://hse.ie/eng/about/Who/clinical/ natclinprog/rheumatologyprogramme/modelofcare.html

Hoving, J. L., van Zweiten, M. C. B., van der Meer, M., Sluiter, J. K., \& FringsDresen, M. H. W. (2013). Work participation and arthritis: A systematic overview of challenges, adaptations and opportunities for interventions. Rheumatology, 52(7), 1254-1264. https://doi.org/10.1093/ rheumatology/ket111

Kane, D., \& Kavanagh, R. (2011). Management of early inflammatory arthritis. Forum. 11, 53-54. Retrieved March 9th, 2016, from https:// www.icgp.ie/assets/65/B165D74B-19B9.../Arthritis_53-54.pdf

Lacaille, D., White, M. A., Backman, C. L., \& Gignac, M. L. (2007). Problems faced at work due to inflammatory arthritis: new insights gained from understanding patients' perspective. Arthritis and Rheumatism, 57(7), 1269-1279. https://doi.org/10.1002/art.23002

Lee, J., \& Kielhofner, G. (2009). Vocational intervention based on the model of human occupation: A review of evidence. Scandinavian Journal of Occupational Therapy, 13(1), 1-14. https://doi.org/10.1080/ 11038120903082260

National Institute of Clinical Excellence (2009). Rheumatoid arthritis: The management of rheumatoid arthritis in adults. Retrieved from https://www.nice.org.uk/guidance/cg79

Prior, Y., \& Hammond, A. (2013). A systematic review of work interventions for people with rheumatoid arthritis. British Journal of Occupational Therapy, 76(Suppl. 1), 125-126.

Prior, Y., \& Hammond, A. (2014). Do occupational therapy services fulfill the work related needs of rheumatology patients in the UK? Annals of the Rheumatic Diseases, 73 (Suppl. 2), 93. https://doi.org/10.1136/ annrheumdis-2014-eular.3407

Tillett, W., de-Vries, C., \& McHugh, N. J. (2012). Work disability in psoriatic arthritis: A systematic review. Rheumatology, 51(2), 275-283. https:// doi.org/10.1093/rheumatology/ker216

Waddell, G., Burton, A., \& Kendall, N. (2008). Vocational Rehabilitation: What Works, for Whom, and When. London: The Stationery Office.

Walker-Bone, K., \& Black, C. (2016). The importance of work participation as an outcome in rheumatology. Rheumatology, 55(8), 1345-1347. https://doi.org/10.1093/rheumatology/kew147

World Federation of Occupational Therapists (2012). Position statement: Vocational rehabilitation. Retrieved from http://www.wfot.org/ ResourceCentre/tabid/132/did/503/Default.aspx

How to cite this article: Codd Y, Stapleton T, Kane D, Mullan R. A survey to establish current practice in addressing work participation with inflammatory arthritis in the Irish clinical setting. Musculoskeletal Care. 2018;16:158-162. https://doi. org/10.1002/msc.1198 